\title{
Clinical evidence of exaggerated inflammation in patients with a cardiogenic shock complicating ST-segment elevation myocardial infarction
}

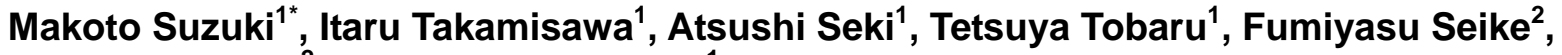 \\ Hideaki Shimizu ${ }^{2}$, Morimasa Takayama ${ }^{1}$ \\ ${ }^{1}$ Department of Cardiovascular Medicine, Sakakibara Heart Institute, Tokyo, Japan; *Corresponding Author: msuzuki@shi.heart.or.jp \\ ${ }^{2}$ Department of Cardiology, Ehime Prefectural Central Hospital, Ehime, Japan
}

Received 23 May 2013; revised 24 June 2013; accepted 19 July 2013

Copyright (C) 2013 Makoto Suzuki et al. This is an open access article distributed under the Creative Commons Attribution License, which permits unrestricted use, distribution, and reproduction in any medium, provided the original work is properly cited.

\section{ABSTRACT}

We characterized the degree of systemic and coronary inflammation and the impact of those on clinical state in patients with a cardiogenic shock complicating first anterior ST-segment elevation myocardial infarction (STEMI). Methods: We recruited 14 consecutive patients with cardiogenic shock (10 men, $69 \pm 12$ years) and 18 well-matched baseline characteristics without shock (17 men, $64 \pm 9$ years) undergoing percutaneous coronary intervention $(\mathrm{PCl})$ for an early phase of a first anterior STEMI in whom plasma level of cardiac enzyme was less elevated. We measured systemic and coronary levels of C-reactive protein, interleukin-6, and angiotensin II, and evaluated the relation of those to myocardial tissue-level reperfusion using both angiographic myocardial blush grade from 0 to 3 , with the highest grade indicating normal myocardial perfusion, and a resolution of the sum of ST-segment elevation in 12-lead electrocardiogram. Results: In-hospital mortality was $57 \%$ in patients with cardiogenic shock and $6 \%$ without shock $(p=0.005)$. Coronary levels of C-reactive protein $(9.2 \pm 6.9$ vs. $1.7 \pm 2.1 \mathrm{mg} / \mathrm{L}, \mathrm{p}=0.001)$, interleukin-6 $(379 \pm 137$ vs. $24 \pm 20 \mathrm{pg} / \mathrm{mL}, \mathrm{p}=$ $0.003)$, and angiotensin II (19 \pm 10 vs. $10 \pm 6$ $\mathrm{pg} / \mathrm{mL}, \mathrm{p}=0.010$ ) were extremely higher in patients with shock than without shock. Interleukin-6 and angiotensin II, but not C-reactive protein, revealed higher in coronary levels than in systemic levels. The presence of both myocardial blush grade $<3$ and ST-segment resolution $<50 \%$, indicating failed myocardial tissuelevel reperfusion, was found in 8 patients with shock and 3 without shock $(57 \%$ vs. $17 \%, p=$ 0.026). A multivariate regression analysis showed culprit coronary levels of angiotensin II as a special association with failed myocardial tissue-level reperfusion $(p=0.012)$. Conclusions: The exaggerated systemic and coronary inflammation, presumably associated with myocardial mal-reperfusion, was presented in patients with a cardiogenic shock complicating first anterior STEMI.

Keywords: Cardiogenic Shock; Myocardial Infarction; Inflammation; Reperfusion; Acidosis

\section{INTRODUCTION}

A presence of cardiogenic shock remains serious limitations to achieve the rewarding clinical benefits in patients with a ST-segment elevation myocardial infarction (STEMI) regardless of the early prompt reperfusion by percutaneous coronary intervention (PCI) [1,2] Because progressive and excessive systemic as well as myocardial tissue-level mal-perfusion may play a crucial role in the pathogenesis of cardiogenic shock [3], we postulated adequate systemic and myocardial tissue-level reperfusion as the key issue to provide great advantages in patients treated with PCI for a cardiogenic shock complicating STEMI.

Reperfusion of a severely ischemic myocardium might result in lethal reperfusion injury, possibly arising from inflammatory reactions in patients with a STEMI $[4,5]$. Recently we also found a critical role of systemic inflammation in the mechanisms of cardio-renal syndrome linked with fatal clinical outcomes in patients with a STEMI [6].

In view of those relations of inflammation to clinical 
outcomes in a STEMI, we investigated our hypothesis that a great exaggeration of systemic and also coronary inflammation may be presented in the setting of a cardiogenic shock complicating STEMI, and those inflammations may play a role in the pathogenesis of mal-reperfusion in patients treated with PCI for a cardiogenic shock complicating STEMI. If correct, future studies should be conducted to identify novel therapeutic targets for exaggerated systemic and coronary inflammation with prompt coronary reperfusion in those with a cardiogenic shock complicating STEMI.

\section{METHODS}

\subsection{Study Patients}

A total of 14 patients with a cardiogenic shock complicating first anterior STEMI and 18 demographic matched patients with a non-shock anterior STEMI were studied. To minimize an influence of myocardial necrosis on coronary levels of inflammation, we enrolled patients in whom plasma levels of cardiac enzyme were less than three times the upper limit of normal levels on admission. Patients recruited in this study were partially enrolled in our previous study [5]. Cardiogenic shock was defined as a systolic blood pressure of less than 90 $\mathrm{mm} \mathrm{Hg}$ or mean arterial pressure $30 \mathrm{~mm} \mathrm{Hg}$ lower than baseline and associated with cyanosis, cold extremities, changes in mental status, persistent oliguria, or congestive heart failure [2].

\subsection{Analysis of Inflammatory Markers and Myocardial Tissue-Level Reperfusion}

PCI with coronary stent deployment was successfully performed using conventional techniques with dual anti-platelet therapy in this study. Aspirated culprit coronary thrombus and peripheral blood were simultaneously sampled to measure coronary and systemic levels of C-reactive protein, interleukin-6, and angiotensin II using commercial available assays [5-8].

In a case of hemodynamic instability, intra-aortic ballsoon counter pulsation and/or percutaneous cardio-pulmonary bypass were actively used. Patients did not undergo intravenous thrombolysis and were not given glycoprotein IIb/IIIa antagonists before PCI. Pre- and post-procedural culprit epicardial coronary flow was evaluated by Thrombolysis in Myocardial Infarction (TIMI) flow grade [9] with an assessment of Rentrop collateral grade [10]. Myocardial tissue-level reperfusion was evaluated by both angiographic myocardial blush grade from 0 to 3 , with the highest grade indicating normal myocardial perfusion, and a resolution of the sum of ST-segment elevation in 12-lead electrocardiogram as reported previously [11]. Failed myocardial tissue-level reperfusion was defined by a presence of both angiographic myocardial blush grade $<3$ and ST-segment resolution $<50 \%$ after PCI [4].

\subsection{Statistical Analysis}

Continuous variables are presented as mean $\pm \mathrm{SD}$, and comparisons between patients with and without cardiogenic shock were made with an unpaired $t$ test or a Mann-Whitney U test, in accordance with the data distribution. Comparisons of continuous data were made with paired t test. Categorical variables were compared with the chi-square test. A multivariate regression analysis was performed to identify an association of coronary levels of inflammation with myocardial tissue-level reperfusion. Statistical significance was set as p values $<$ 0.05 . Our institutional review board approved the study protocol. All patients or an immediate family member provided written, informed consent to participate in the present study at the time of admission.

\section{RESULTS}

A total of eight patients with cardiogenic shock and one without shock were in-hospital dead (57\% vs. $6 \%$, p $=0.005)$. A quite difference in blood pressure, Killip class, and arterial acid-base status on admission with well-matched other demographic characteristics were found between patients with and without cardiogenic shock (Table 1). Those with cardiogenic shock were more quickly treated with PCI in part with mechanical hemodynamic support, but highly complicated with failed myocardial tissue-level reperfusion (Figure 1(a)).

Interleukin-6 (66 $\pm 95 \mathrm{pg} / \mathrm{mL}$ vs. $48 \pm 82 \mathrm{pg} / \mathrm{mL}, \mathrm{p}=$ $0.005)$ and angiotensin II $(14 \pm 9 \mathrm{pg} / \mathrm{mL}$ vs. $8 \pm 6 \mathrm{pg} / \mathrm{mL}$, $\mathrm{p}=0.003)$, but not C-reactive protein $(3.2 \pm 3.3 \mathrm{mg} / \mathrm{L}$ vs. $4.4 \pm 6.2 \mathrm{mg} / \mathrm{L}, \mathrm{p}=0.101$ ), revealed higher in coronary levels than in systemic levels. Systemic levels of C-reactive protein showed higher in patients with cardiogenic shock than in those without shock $(8.9 \pm 2.5 \mathrm{mg} / \mathrm{L}$ vs. 2.0 $\pm 2.3 \mathrm{mg} / \mathrm{L}, \mathrm{p}=0.011)$. Furthermore, coronary levels of C-reactive protein $(9.2 \pm 6.9 \mathrm{mg} / \mathrm{L}$ vs. $1.7 \pm 2.1 \mathrm{mg} / \mathrm{L}, \mathrm{p}$ $=0.001)$ interleukin $-6(379 \pm 137 \mathrm{pg} / \mathrm{mL}$ vs. $24 \pm 20$ $\mathrm{pg} / \mathrm{mL}, \mathrm{p}=0.003)$ and angiotensin II $(19 \pm 10 \mathrm{pg} / \mathrm{mL}$ vs. $10 \pm 6 \mathrm{pg} / \mathrm{mL}, \mathrm{p}=0.01$ ) (Figure 1(b)) were extremely higher in patients with cardiogenic shock than those without shock. A linear relation between worsen base excess and systemic levels of C-reactive protein was found (Figure 2(a)). With a roughly inverse relation of coronary levels of angiotensin II to a resolution of STsegment elevation (Figure 2(b)), a multivariate regression analysis showed coronary levels of angiotensin II as a special association with failed myocardial tissue-level reperfusion $(95 \%$ confidence interval $0.008-0.060, p=$ 0.012). 
Table 1. Demographic and angiographic characteristics of patients with a first anterior STEMI, in accordance with the presence or absence of cardiogenic shock.

\begin{tabular}{|c|c|c|c|}
\hline & \multicolumn{2}{|c|}{ Cardiogenic shock } & \multirow{3}{*}{$\mathrm{p}$ Value } \\
\hline & Yes & No & \\
\hline & $(\mathrm{n}=14)$ & $(\mathrm{n}=18)$ & \\
\hline Age, yr & $69 \pm 12$ & $64 \pm 9$ & 0.142 \\
\hline Male sex, no. (\%) & $10(71)$ & $13(72)$ & 0.198 \\
\hline Body mass index, $\mathrm{kg} / \mathrm{m}^{2}$ & $24 \pm 3$ & $24 \pm 3$ & 0.680 \\
\hline Systolic blood pressure, $\mathrm{mm} \mathrm{Hg}$ & $94 \pm 19$ & $143 \pm 21$ & 0.001 \\
\hline Diastolic blood pressure, $\mathrm{mm} \mathrm{Hg}$ & $52 \pm 15$ & $86 \pm 15$ & 0.001 \\
\hline Heart rate, beats/min & $91 \pm 20$ & $82 \pm 12$ & 0.135 \\
\hline Killip class & $4 \pm 0$ & $1.3 \pm 0.5$ & 0.001 \\
\hline Creatine kinases-MB on admission, IU/L & $32 \pm 25$ & $24 \pm 26$ & 0.383 \\
\hline Arterial pH & $7.29 \pm 0.21$ & $7.44 \pm 0.05$ & 0.001 \\
\hline $\mathrm{PaO}_{2}, \mathrm{~mm} \mathrm{Hg}$ & $142 \pm 105$ & $111 \pm 34$ & 0.355 \\
\hline $\mathrm{PaCO}_{2}, \mathrm{~mm} \mathrm{Hg}$ & $39 \pm 11$ & $36 \pm 5$ & 0.516 \\
\hline Base excess, mmol/L & $-7.5 \pm 5.9$ & $-0.7 \pm 2.1$ & 0.001 \\
\hline Hypertension, no. (\%) & $3(21)$ & $8(44)$ & 0.325 \\
\hline Dyslipidemia, no. (\%) & $3(21)$ & $6(33)$ & 0.729 \\
\hline Cigarette smokers, no. (\%) & $5(36)$ & $11(61)$ & 0.285 \\
\hline Diabetes mellitus, no. (\%) & $8(57)$ & $6(33)$ & 0.323 \\
\hline Hospital arrival to PCI, min & $32 \pm 29$ & $66 \pm 30$ & 0.001 \\
\hline Multi-vessel diseases, no. (\%) & $10(71)$ & $2(11)$ & 0.002 \\
\hline Intra-aortic balloon pumping, no (\%) & $11(79)$ & $0(0)$ & 0.001 \\
\hline Percutaneous cardio-pulmonary bypass, no (\%) & $2(14)$ & $0(0)$ & 0.358 \\
\hline Initial TIMI flow grade 0 , no. (\%) & $9(64)$ & $10(56)$ & 0.892 \\
\hline Final TIMI flow grade 3, no. (\%) & $8(57)$ & $13(72)$ & 0.606 \\
\hline Rentrop's collateral flow grade $2 / 3$, no. ( $\%$ ) & $1(7)$ & $2(11)$ & 0.999 \\
\hline Resolution of ST-segment elevation, $\%$ & $33 \pm 28$ & $54 \pm 25$ & 0.032 \\
\hline Myocardial blush grade $0 / 1$, no (\%) & $6(43)$ & $2(11)$ & 0.032 \\
\hline
\end{tabular}

Plus-minus values are mean \pm SD. PCI, percutaneous coronary intervention, TIMI, Thrombolysis in Myocardial Infarction.

\section{DISCUSSION}

In this study, we found both systemic and coronary levels of inflammation were markedly elevated when complicated with cardiogenic shock in patients with a first anterior STEMI. Enhanced coronary inflammation, especially coronary levels of angiotensin II, was likely associated with high incidence of failed myocardial tissue-level reperfusion in those with a cardiogenic shock complicating first anterior STEMI. Interestingly, a degree of metabolic acidosis (e.g. base excess) was sharply associated with systemic levels of inflammation (e.g. systemic levels of C-reactive protein). Taken together, we considered systemic and coronary exaggerated inflammation as one of the pathogenesis of a cardiogenic shock complicating STEMI, which might be associated with metabolic crisis and may have a critical role in failed myocardial tissue-level reperfusion leading fatal clinical outcomes.

Previously we reported a possible association of coronary inflammation and vulnerable characteristics of culprit plaque with impaired myocardial tissue-level reperfusion in patients with a STEMI [5]. We also notified a relationship between systemic and coronary levels of inflammation in those with a STEMI [8]. More recently, we suggested a critical role of systemic inflammatory response syndrome as the pathogenesis of cardio-renal syndrome in a STEMI [6]. Overall, from the viewpoint of a STEMI as an inflammatory disorder [12], cardiogenic shock mostly causes a vicious inflammatory attack on both systemic and coronary levels, which may potentially related with miserable myocardial tissue-level reperfusion and disappointed clinical outcomes regardless of successfully undergoing prompt PCI. 
a

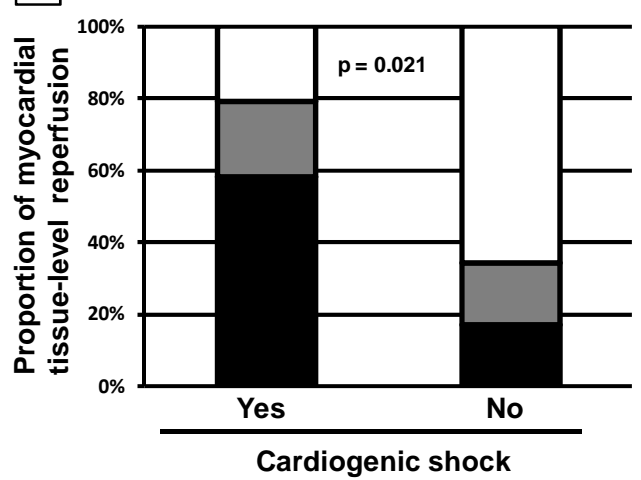

b

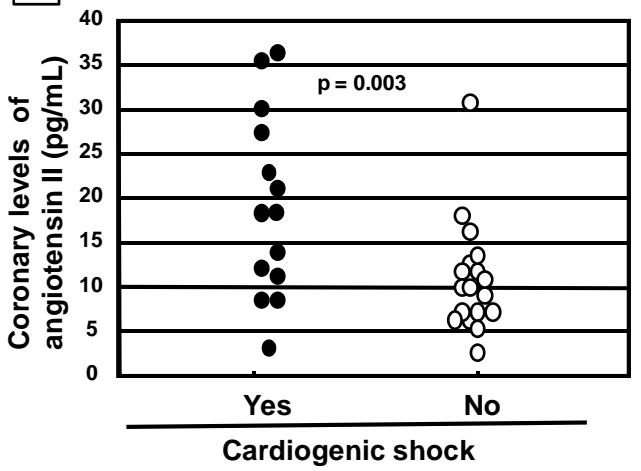

Figure 1. (a) Proportion of myocardial tissue-level reperfusion in patients with a first anterior STEMI, in accordance with the presence or absence of cardiogenic shock. STEMI denotes ST-segment elevation myocardial infarction. White bar was a proportion of the presence of both ST-segment resolution $\geq 50 \%$ and myocardial blush grade 3, indicating well myocardial tissue-level reperfusion, gray bar presented a proportion of the presence of either ST-segment resolution $<50 \%$ or myocardial blush grade $<3$, and black bar revealed a proportion of the presence of both ST-segment resolution $<50 \%$ and myocardial blush grade $<3$, indicating failed myocardial tissue-level reperfusion. (b) Coronary levels of angiotensin II in patients with a first anterior STEMI, in accordance with the presence or absence of cardiogenic shock.
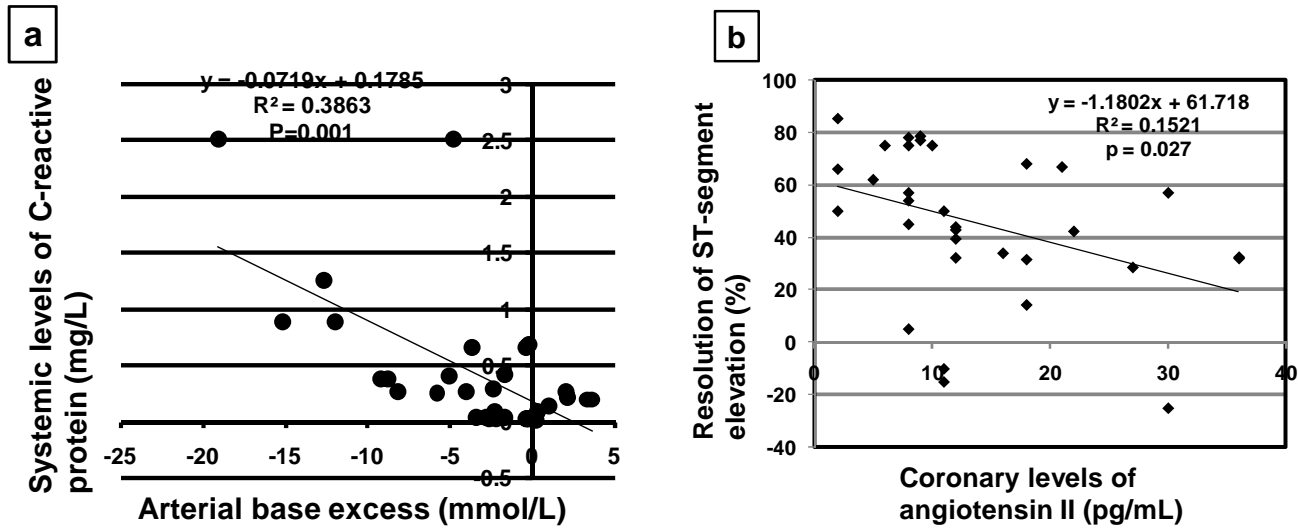

Figure 2. (a) Relationship between arterial base excess on admission and systemic levels of C-reactive protein in patients with a first anterior STEMI with and without cardiogenic shock. STEMI denotes ST-segment elevation myocardial infarction. (b) Relationship between coronary levels of angiotensin II and resolution of ST-segment elevation in patients with a first anterior STEMI with and without cardiogenic shock.

Systemic mal-perfusion due to cardiogenic shock elicits microcirculatory and mitochondrial distress syndrome leading metabolic crisis, which may play a role in the induction of systemic inflammation [13]. Extracellular acidosis is considered to promote the acute inflammatory process through an enhanced immune response, which can be explained by extended functional lifespan of mononuclear cells $[12,14]$. Extracellular acidosis can also cause a hyper-oxidative state through increased production of superoxide from inflammatory cells [14]. Additionary, increased extracellular protons increase intracellular $\mathrm{Na}^{+}$and $\mathrm{Ca}^{2+}$ through $\mathrm{Na}^{+}-\mathrm{H}^{+}$and $\mathrm{Na}^{+}-\mathrm{Ca}^{2+}$ exchangers, and then the induced $\mathrm{Ca}^{2+}$ overload may exaggerate the occurrence of reperfusion injury at both sys- temic and coronary levels [15]. Based on the scientific feature that cellular injury can release endogenous damage-associated molecular patterns (i.e. mitochondrial structures released by ischemia and/or reperfusion injury) to activate innate immunity [16], those mediators may also elicit systemic inflammatory injury.

Cardiogenic shock is well-recognized as the leading cause of death in patients hospitalized with a STEMI even in the era of early prompt PCI [1]. So far aggressive approaches such as the early use of circulatory support could not demonstrate to ameliorate fatal clinical outcomes in those with a cardiogenic shock complicating STEMI $[17,18]$. Thus, we believe that future studies are encouraged to calm down a life-threatening exaggerated 
inflammation to ameliorate miserable clinical outcomes in patients with a cardiogenic shock complicating STEMI.

This study has several limitations. We recruited a small number of patients with an early phase of STEMI who showed less elevation of cardiac enzyme to exclude inflammation from myocardial necrosis. This may have a possibility of our knowledge to fulfill a piece of those with a cardiogenic shock complicating STEMI. Second, we evaluated arterial systemic levels of base excess as a simple marker of metabolic acid-base disturbance. However, we did not define the metabolic acid-base disturbance exactly because of its complex [19]. This disturbance may occur from a variety of organic or inorganic fixed acids wherever there is inadequate oxygen delivery to support energy metabolism. Importantly, arterial levels of acid-base disturbance may not reflect cellular levels of it precisely. And finally, this study did not directly prove the exact mechanisms about the relation between intensive inflammation and fatal clinical outcomes in patients with a cardiogenic shock complicating STEMI. As mentioned in our review article [12] that inflammation plays a bipolar action as injury and repair in the pathogenesis of acute coronary syndromes, we need to understand the precise roles of inflammation in a cardiogenic shock complicating STEMI which enable us to challenge these critical disorder.

\section{CONCLUSION}

In conclusion, we showed a clinical evidence that the exaggerated systemic and coronary inflammation, presumably associated with myocardial mal-reperfusion, was presented in patients with a cardiogenic shock complicating first anterior STEMI.

\section{ACKNOWLEDGEMENTS}

We thank Akimi Mori and Mariko Ishizaki for their expert assistance in the preparation of this manuscript.

\section{REFERENCES}

[1] Babaev, A., Frederick, P.D., Pasta, D.J., Every, N., Sichrovsky, T., Hochman, J.S. and NRMI Investigators. (2005) Trends in management and outcomes of patients with acute myocardial infarction complicated by cardiogenic shock. JAMA, 294, 448-454.

http://dx.doi.org/10.1001/jama.294.4.448

[2] Suzuki, M., Fujita, S., Seike, F., Enomoto, D. and Honda, K. (2013) Wide QRS Complex and myocardial tissue-level reperfusion in cardiogenic shock complicating STsegment elevation myocardial infarction. Gazzetta Medica Italiana, 172, 137-143.

[3] Reynold, H.R. and Hochman, J.S. (2008) Cardiogenic shock: Current concepts and improving outcomes. Circulation, 117, 686-697.
http://dx.doi.org/10.1161/CIRCULATIONAHA.106.6135 $\underline{96}$

[4] Suzuki, M., Sakaue, T., Tanaka, M., Hirose, E., Saeki, H., Matsunaka, T., Hiramatsu, S. and Kazatani, Y. (2006) Association between right bundle branch block and impaired myocardial tissue-level reperfusion in patients with acute myocardial infarction. Journal of the American College of Cardiology, 47, 2122-2124. http://dx.doi.org/10.1016/j.jacc.2006.02.034

[5] Suzuki, M., Shimizu, H., Miyoshi, A., Takagi, Y., Sato, S. and Nakamura, Y. (2011) Association of coronary inflammation and angiotensin II with impaired microvascular reperfusion in patients with ST-segment elevation myocardial infarction. International Journal of Cardiology, 146, 254-256.

http://dx.doi.org/10.1016/j.ijcard.2010.10.067

[6] Suzuki, M., Seike, F., Miyoshi, A., Shimizu, H., Takagi, Y., Sato, S. and Honda, K. (2013) Critical role of systemic inflammation in patients with ST-segment elevation myocardial infarction complicated with renal dysfunction. International Journal of Cardiology, Epub ahead of print.

[7] Suzuki, M., Inaba, S., Nagai, T., Tatsuno, H. and Kazatani, Y. (2003) Relation of C-reactive protein and interleukin-6 to culprit coronary artery plaque size in patients with acute myocardial infarction. American Journal of Cardiology, 91, 331-333. http://dx.doi.org/10.1016/S0002-9149(02)03162-4

[8] Suzuki, M., Saito, M., Nagai, T., Saeki, H. and Kazatani, Y. (2006) Systemic versus coronary levels of inflammation in acute coronary syndromes. Angiology, 57, 459463. http://dx.doi.org/10.1177/0003319706290742

[9] The TIMI Study Group (1985) The Thrombolysis in Myocardial Infarction (TIMI) trial: Phase I findings. The New England Journal of Medicine, 312, 932-936. http://dx.doi.org/10.1056/NEJM198504043121437

[10] Rentrop, K.P., Cohen, M., Blanke, H. and Phillips, R.A. (1985) Changes in collateral channel filling immediately after controlled coronary artery occlusion by an angioplasty balloon in human subjects. Journal of the American College of Cardiology, 5, 587-592. http://dx.doi.org/10.1016/S0735-1097(85)80380-6

[11] Poli, A., Fetiveau, R., Vandoni, P., del Rosso, G., D’Urbano, M., Seveso, G., Cafiero, F. and De Servi, S. (2002) Integrated analysis of myocardial blush and ST-segment elevation recovery after successful primary angioplasty. Real-time grading of microvascular reperfusion and prediction of early and late recovery of left ventricular function. Circulation, 106, 313-318. http://dx.doi.org/10.1161/01.CIR.0000022691.71708.94

[12] Suzuki, M. (2012) Acute coronary syndromes as autoinflammatory disorders. Current Pharmaceutical Design, 18, 4370-4384. http://dx.doi.org/10.2174/138161212802481228

[13] Trevani, A.S., Andonegui, G., Giordano, M., Lopez, D.H., Gamberale, R., Minucchi, F. and Geffner, J.R. (1999) Extracellular acidification induces human neutrophil activetion. Journal of Immunology, 162, 4849-4857.

[14] Carbonell, T., Ródenas, J., Alfaro, V., Mitjavila, M.T. and Palacios, L. (2002) Extracellular pH affects inflammatory 
cell production of superoxide and nitric oxide. Journal of Physiology and Biochemistry, 58, 115-120. http://dx.doi.org/10.1007/BF03179847

[15] Yellon, D.M. and Hausenloy, D.J. (2007) Myocardial reperfusion injury. The New England Journal of Medicine, 357, 1121-1135.

http://dx.doi.org/10.1056/NEJMra071667

[16] Zhang, Q., Raoof, M., Chen, Y., Sumi, Y., Sursal, T., Junger, W., Brohi, K., Itagaki, K. and Hauser, C.J. (2010) Circulating mitochondrial DAMPs cause inflammatory response to injury. Nature, 464, 104-107. http://dx.doi.org/10.1038/nature08780

[17] Thiele, H., Sick, P., Boudriot, E., Diederich, K.W., Hambrecht, R., Niebauer, J. and Schuler, G. (2005) Randomized comparison of intra-aortic balloon support with a percutaneous left ventricular assist device in patients with revascularized acute myocardial infarction complicated by cardiogenic shock. European Heart Journal, 26, 12761283. http://dx.doi.org/10.1093/eurheartj/ehi161

[18] Thiele, H., Zeymer, U., Neumann, F.J., Ferenc, M., Olbrich, H.G., Hausleiter, J., Richardt, G., Hennersdorf, M. Empen, K., Fuernau, G., Desch, S., Eitel, I., Hambrecht, R., Fuhrmann, J., Bohm, M., Ebelt, H., Schneider, S., Schuler, G., Werdan, K. and IABP-SHOCK II Trial Investigators (2012) Intraaortic balloon support for myocardial infarction with cardiogenic shock. The New England Journal of Medicine, 367, 1287-1296. http://dx.doi.org/10.1056/NEJMoa1208410

[19] Adrogue, H.J. and Madias, N.E. (1998) Management of life-threatening acid-base disorders. First of two parts. The New England Journal of Medicine, 338, 26-34. http://dx.doi.org/10.1056/NEJM199801013380106 